\title{
Production kinetics of polyhydroxyalkanoates by using Pseudomonas aeruginosa gamma ray mutant strain EBN-8 cultured on soybean oil
}

\author{
Sharjeel Abid ${ }^{1} \cdot$ Zulfiqar Ali Raza $^{1} \cdot$ Tanveer Hussain $^{1}$
}

Received: 7 March 2016/ Accepted: 3 June 2016/Published online: 23 June 2016

(c) The Author(s) 2016. This article is published with open access at Springerlink.com

\begin{abstract}
The purpose of present study was to optimize polyhydroxyalkanotes (PHAs) production in a gamma ray mutant strain of Pseudomonas aeruginosa grown on soybean oil in minimal salts media under shake flask conditions. The production kinetics was studied by sampling on daily basis for 6 days to investigate the best conditions for PHAs production like biomass estimation, carbon source utilization and PHAs yield. The PHA accumulation was observed up to $50.27 \%(\mathrm{w} / \mathrm{w})$ of cell dry mass. The Pseudomonas species synthesized medium chain length PHA copolyester as per identified by LCMS and confirmed by FTIR spectroscopy. The ESI-MS analysis exhibited the major polyhydroxybutyrate with a molecular mass of $\mathrm{m} / \mathrm{z}$ 448.5 .
\end{abstract}

Keywords PHAs $\cdot$ Polyhydroxyalkanoates $\cdot$ Pseudomonas aeruginosa $\cdot$ Shake flask . Soybean oil

\section{Introduction}

Polyhydroxyalkanoates (PHAs) are one of the major candidates to replace petroleum derived polyesters due to their extraordinary properties and they have one of the widest range of molecular masses from $1 \times 10^{4}$ to $1 \times 10^{6} \mathrm{amu}$ (Chen 2010). These are high molecular mass biological polyesters synthesized in many living organisms. The properties of PHAs cover wide range from materials like poly (propylene) to elastomeric materials. Their diverse

Zulfiqar Ali Raza

zarazapk@yahoo.com

1 Chemistry Research Laboratory, National Textile University, Faisalabad 37610, Pakistan properties are either due to the distant variation between ester linkages or the length of pendant groups extending from back bone (Williams et al. 1999). Properties of conventional plastics as well as PHAs can be tailored as desired from packing materials to highly elastic ones like coatings but the PHAs have the edge of being biodegradable as well as they are produced from the sources which are renewable (Loo and Sudesh 2007).

Plants and different types of microorganisms can produce PHAs but cell dry mass (CDM) of less than $10 \%$ (w/ w) is observed in plants, however bacteria can accumulate as high as $90 \%(\mathrm{w} / \mathrm{w})$. This low accumulation in plants is due to the fact that greater than $10 \%(\mathrm{w} / \mathrm{w})$ accumulation generally has a negative impact on plant growth (Verlinden et al. 2007; Tan et al. 2014). On the other hand, more than 250 different bacterial strains can produce PHAs under various conditions and they generate PHAs with different levels of quality, yield and efficiency (Pollet and Averous 2011).

Conventional plastics produced from petrochemical sources are associated with the main issues of disposal and production from limited resources of petrochemicals resulting in the accumulation of large waste in the environment (landfill and sea water). Occurrence of PHAs was reported by Lemoigne in 1920s but the main reason of preferring conventional petrochemical based plastics over bioplastics was the low cost of formers and high cost of latters (Verlinden et al. 2007). One of the major factors for high cost of PHAs is the high cost of carbon source the researchers, therefore, are trying to explore some inexpensive sources like waste frying oils to reduce the cost associated with PHAs production (Lee et al. 2008). Pseudomonas sp. has been reported to produce 37.34 and $23.52 \%(\mathrm{w} / \mathrm{w})$ PHAs from corn oil and waste frying oils, respectively (Song et al. 2008). 
Agriculture and food industries dispose off a large amount of carbon and other nutrients rich waste which can be used for the economical production of PHAs as this waste can be utilized as renewable source by many microorganisms hence giving more ecological and attractive alternative usage than disposal of this waste into the environment (Song et al. 2008; Chee et al. 2010; Prasad and Sethi 2013). Plant oils (like palm oil, soybean oil, sunflower oil etc.) are preferred to sugars as sole carbon source for PHAs production as they are cheaper and produce more quantity of PHAs per gram of carbon source, for instance, $0.3-0.4 \mathrm{~g}$ of PHAs have been reported by $1 \mathrm{~g}$ of glucose; on the other hand, plant oils yield $0.6-0.8 \mathrm{~g}$ of PHAs per gram of oil. This higher production could be attributed to the more carbon content per unit mass of plant oils as compared to sugars (Chee et al. 2010). The higher catabolism rate of lipid substrates (beta-oxidation at lipids) than other substrates (Muhr et al. 2013a, b) and the fact that these saturated and unsaturated fats can easily be metabolized by microorganisms to synthesize PHAs (Koller et al. 2012).

For the batch production of PHAs in bacterial cells, two modes are normally used. In the first, accumulation of PHAs starts at the exponential phase and continues until the late stationary phase and is known as one stage batch cultivation. In the second, cultivation of bacteria is done in a separate growth favoring environment and when the cells are enriched, they are transferred to the PHAs accumulation phase where nutrient depletion is used for this purpose (Kumar and Abe 2010). For the survival of cells when bacteria face starvation, fluctuations in environmental conditions, giving response to sporulation or encystment, bacteria store important nutrients where PHAs are one of the major such storage compounds (Haba et al. 2007).

For the production of PHAs within bacterial cells, the carbon sources are comprehended and then transmuted into hydroxyalkanoates followed by polymerization into PHAs and stored in cell cytoplasm as water insoluble granules. These granules appear as spherical particles with clear boundaries and are electron transparent. These PHAs in granules form are kept in amorphous state in vivo otherwise if crystallized these granules cannot serve as storage compound for the host bacterial cell producing it (Loo and Sudesh 2007). Pseudomonas sp. is one of the most studied microorganism for PHAs accumulation (Jiang et al. 2008). $P$. aeruginosa generally produce medium chain length $(\mathrm{mcl})$ PHAs (Soberon-Chavez et al. 2005a). Various studies on Pseudomonas species showed that different carbon sources like alkanes, alkene, carboxylic acids, alcohols, carbohydrates and others could be used for mcl PHAs production (Silva-Queiroz et al. 2009). P. aeruginosa could produce PHAs and rhamnolipids simultaneously when subjected to nitrogen limited conditions (Marsudi et al. 2008).
The EBN-8 gamma ray mutant of $P$. aeruginosa has previously been studied for enhanced production of biosurfactant (Raza et al. 2014) but has not been studied for the production of PHAs when grown on soybean oil. The aim of present study is to investigate production kinetics of PHAs by using a Pseudomonas aeruginosa mutant strain grown on soybean oil as carbon source under shake flask conditions. The synthesized polymer was isolated, purified and chemically analyzed for identification.

\section{Materials and methods}

\section{Materials}

Soybean cooking oil was purchased from Hamza vegetable oil refinery and ghee mills (Pvt.) Ltd, Lahore-Pakistan. All the chemicals used in this study were of analytical grade. $\mathrm{KH}_{2} \mathrm{PO}_{4}, \mathrm{~K}_{2} \mathrm{HPO}_{4}, \mathrm{FeSO}_{4} .7 \mathrm{H}_{2} \mathrm{O}$, chloroform, methanol and acetone were purchased from SigmaAldrich ${ }^{\circledR} \cdot \mathrm{CaCl}_{2} \cdot 2 \mathrm{H}_{2} \mathrm{O}$ and $\mathrm{MgSO}_{4} \cdot 7 \mathrm{H}_{2} \mathrm{O}$ were purchased from Riedel-de Haen ${ }^{\circledR}$, and $\mathrm{NaNO}_{3}$ from Merck ${ }^{\circledR}$. Petroleum ether was supplied by Fisher ${ }^{\circledR}$ chemicals.

\section{Microorganism}

The gamma ray induced mutant strain of Pseudomonas aeruginosa designated as EBN-8 (Iqbal et al. 1995) used in this study was kindly donated by National Institute for Biotechnology and Genetic Engineering (NIBGE), Faisalabad-Pakistan. The inoculum was prepared by suspending the cells of bacteria in normal saline $(0.89 \%, \mathrm{w} / \mathrm{v}, \mathrm{NaCl})$ and set an optical activity of 0.7 at $660 \mathrm{~nm}$. This suspension was used as inoculum during the present study.

\section{Shake flask experiment}

For the shake flask experiments, following recipe $(\mathrm{g} / \mathrm{l})$ was used for minimal salts media prepared in distilled water: $\mathrm{KH}_{2} \mathrm{PO}_{4}$ (0.07), $\mathrm{K}_{2} \mathrm{HPO}_{4}(0.13), \mathrm{NaNO}_{3}(0.2), \mathrm{MgSO}_{4}$. $7 \mathrm{H}_{2} \mathrm{O}$ (0.03), $\quad \mathrm{CaCl}_{2} .2 \mathrm{H}_{2} \mathrm{O} \quad(0.01)$ and $\mathrm{FeSO}_{4} .7 \mathrm{H}_{2} \mathrm{O}$ (0.0001). The $\mathrm{pH}$-value of the solution was adjusted to 7 when required and $100 \mathrm{ml}$ of solution were shifted in separate $250 \mathrm{ml}$ Erlenmeyer flasks and sterilized at $121{ }^{\circ} \mathrm{C}$ for $15 \mathrm{~min}$ in an autoclave (WiseClave ${ }^{\circledR}$; WAC-60, Korea). Three concentrations of soybean oil i.e., 1, 2 and $3 \%(\mathrm{v} / \mathrm{v})$ were used. The inoculum $(1 \%, \mathrm{v} / \mathrm{v})$ was added and the flasks were placed on an orbital shaker (WiseShake ${ }^{\circledR}$; SHO-2D, Daihan, Korea) at $150 \mathrm{rpm}$ and $37 \pm 1{ }^{\circ} \mathrm{C}$.

Sampling was carried out up to 6th day of incubation and on each day different process attributes were monitored to optimize the production conditions of PHAs including: carbon source utilization (w/w \%), biomass 
yield (g/l) and PHA yield (g/l). The experiments were conducted in triplicate and the results reported are the average of three concordant readings.

\section{Carbon source utilization}

For the optimization of PHAs production, carbon source consumption is one of the important parameters to study as it is one of the cost determining factors. For carbon source utilization calculations, cell free culture broth (CFCB) was used. An aliquot of $50 \mathrm{ml}$ of CFCB was washed with 1:2 $(\mathrm{v} / \mathrm{v})$ petroleum ether and the organic layer was separated by using a separating funnel. The organic solvent layer containing the soybean oil was concentrated on a rotary evaporator machine (Strike ${ }^{\circledR}$ 202, STEROGLASS, Italy) at $60{ }^{\circ} \mathrm{C}$ to a constant mass. The carbon source utilization was calculated by the Eq. 1:

Carbon source utilization (w/w \%)

$$
=\left(\frac{\text { Initial oil }- \text { Residual oil }}{\text { Initial oil }}\right) \times 100 \text {. }
$$

\section{Biomass estimation}

An aliquot $(20 \mathrm{ml})$ from the sample flask was centrifuged at $10,000 \mathrm{rpm}$ and $4{ }^{\circ} \mathrm{C}$ by using a refrigerated centrifuge machine (MSE, Harrier 18/80R, England) to collect the cell pellet. The pallet was washed with $n$-hexane to remove any oil traces adhered to the cells and re-suspended using a vortex shaker (WiseMix ${ }^{\circledR}$; VM-10 by Daihan, Korea) and filtered through Whatman ${ }^{\circledR}$ Sigma-Aldrich filter paper. The filter paper was pre-weighed before filtration and after filtration to a constant dry mass using moisture analyzer (UniBloc moisture analyzer, model MOC63u by SHIMADZU, Japan). The cell dry mass (CDM) was calculated by using Eq. 2:

$\mathrm{CDM}=W_{2}-W_{1}$,

where, $W_{2}$ is final dry mass of filter paper including cell pallet and $W_{1}$ is initial dry mass of filter paper without pallet.

\section{Extraction of PHA from cells}

Solvent extraction method was used for the extraction of PHAs from the cells of $P$. aeruginosa as this method does not degrade the polymer (Jacquel et al. 2008). The cells were collected by centrifugation at $10,000 \mathrm{rpm}$ and $4{ }^{\circ} \mathrm{C}$ for $10 \mathrm{~min}$. Acetone washing was used to remove any organics from the cell surface (Brown 1996). The acetone washed cells were subjected to re-washing with an anionic surfactant Triton X-100 to make cells permeable and extract the organelles (Koley and Bard 2010). Then, the cells were freeze dried for overnight using Heto Power Dry LL1500 freeze dryer (Thermo Electron Corporation, USA). These cells were then re-suspended to $50 \mathrm{ml}$ chloroform, shifted in a $250 \mathrm{ml}$ flask and placed on the orbital shaker at $180 \mathrm{rpm}$ at $30{ }^{\circ} \mathrm{C}$ for $24 \mathrm{~h}$ for the extraction of bio-polymer. Then, the cell debris was removed through Whatman ${ }^{\circledR}$ filter paper and the filtrate was concentrated using the rotary evaporator. Then, chilled methanol was added (1:3) drop wise to precipitate PHA polymer (Tan et al. 2014). A milky precipitate containing solution (chloroform and methanol) was rotary evaporated and the concentrate containing the PHA polymers was weighed to a constant mass at $60{ }^{\circ} \mathrm{C}$ (Jiang et al. 2008).

\section{Production kinetics}

Production kinetics of fermentation was studied by calculating the product yield with respect to substrate consumption $Y_{\mathrm{P} / \mathrm{S}}(\mathrm{g} / \mathrm{g})$, product yield with respect to biomass $Y_{\mathrm{P} / \mathrm{X}}(\mathrm{g} / \mathrm{g})$, biomass yield related to substrate consumption $Y_{\mathrm{X} / \mathrm{S}}(\mathrm{g} / \mathrm{g})$ and volumetric productivity $P_{\mathrm{V}}(\mathrm{g} / \mathrm{l} / \mathrm{h})$ of the culture media (Aiba et al. 1973).

\section{Fourier transform infrared spectroscopy (FTIR)}

FTIR (Bruker, Tensor 27) was used to analyze the produced PHA polymer as it is one of the most used characterization technique for identification of polymers (Chalmers et al. 1996; Koller and Rodríguez-Contreras 2015).

\section{Liquid chromatography-Mass spectroscopy (LC-MS)}

The PHB (or PHA) matrix was prepared in chloroform for its ESI chemical analysis on a double focusing mass spectrometer (LTQ XL, Thermo electron Corporation USA) both in positive and negative ion modes equipped with a liquid chromatograph (Finnigan Surveyor, Thermo electron Corporation, USA) at the running conditions of: capillary temperature $280{ }^{\circ} \mathrm{C}$, sheath gas flow rate 25 , auxiliary gas flow rate 5 , tube lenz $70 \mathrm{~V}$, source voltage $3.5 \mathrm{kV}$ and flow rate $10 \mu \mathrm{l} / \mathrm{min}$.

\section{Results and discussion}

Extensive research is being performed on PHAs due to many advantageous properties of the bio-polymer over conventional petrochemical based plastics. Pseudomonas species which belong to the Gram-negative bacteria are well known to accumulate PHAs when grown on different 
substrates under favorable growth conditions. One of the major cost factors in bacterial fermentation is carbon source (Sudesh 2012). For the optimization of present study carbon source utilization, biomass formation and PHAs production has been calculated.

\section{Carbon source utilization}

The amount of carbon source utilized was checked by measuring the residual oil contents in the CFCB. The carbon source utilization results are shown in Fig. 1. P. aeruginosa has been reported for the production of biosurfactant (Haba et al. 2000; Hori et al. 2002; Marsudi et al. 2008; Soberon-Chavez et al. 2005b). The EBN-8 gamma ray mutant used in this study had also been reported to produce of rhamnolipids and with each passing day of incubation, an increased production of rhamnolipids was reported which resulted in a decrease of surface tension of the culture broth (Raza et al. 2006). The reduced surface tension attributed more access of bacteria to the carbon source which was not easily accessible on first day of incubation when no rhamnolipids were produced. Thus, the carbon source utilization increased from 1st day of incubation to 6th day of incubation due to more rhamnolipids production as well as increased concentration of bacteria day by day on all three concentrations but maximum utilization of soybean oil was $78.35 \%(\mathrm{w} / \mathrm{w})$ at 6 th day of incubation when $1 \%(\mathrm{v} / \mathrm{v})$ soybean oil was used as sole carbon source. When 2 and $3 \%(\mathrm{v} / \mathrm{v})$ of soybean oil was used, maximum utilizations were 59.61 and $50.7 \%(\mathrm{w} / \mathrm{w})$, respectively. This could be attributed to the fact that initial concentration of the soybean oil varied hence the utilization of soybean oil too. The concentration of soybean oil available to the 2 and $3 \%(\mathrm{v} / \mathrm{v})$ cultures were high resulting in less oil utilization overall than $1 \%(\mathrm{v} / \mathrm{v})$ cultures. Irrespective of the concentration of the soybean oil used for growth of bacteria, the trend of increased utilization was observed which is shown in Fig. 1; as the

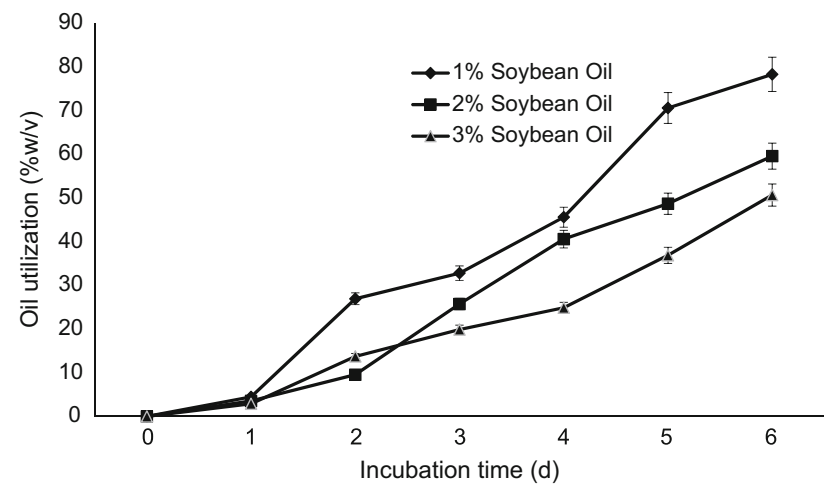

Fig. 1 Carbon source utilization during incubation under shake flask conditions number of bacterial cells increased, the requirement of carbon source for growth increased and production of rhamnolipids increased access of bacteria to hydrophobic carbon source.

\section{Biomass formation}

The biomass was measured for the different concentrations of carbon sources fed for bacterial growth. The maximum CDM achieved was 1.9, 2.2 and $1.87 \mathrm{~g} / \mathrm{l}$ for 1,2 and $3 \%$ (v/v) of soybean oil, respectively (Fig. 2). With each passing day, the CDM increased irrespective of the concentration of the soybean oil though the relationship was not linear, the maximum value was observed on the 6th day of incubation. The optimum concentration was determined to be $2 \%(\mathrm{v} / \mathrm{v})$ on the basis of the results as described in Fig. 2. On moving from 1 to $2 \%$ (v/v) concentration of soybean oil, the CDM increased but it decreased when $3 \%$ $(\mathrm{v} / \mathrm{v})$ soybean oil was used. This finding is in accordance with the work previously published on $P$. aeruginosa where increasing the concentration of soybean oil led to the death of microorganism (Khandpur et al. 2012). Different strains of Pseudomonas have been reported for PHA production using oily substrates. For instance, 5.8-9.7 g/l of $\mathrm{CDM}$ has been observed in $P$. aeruginosa 47T2 (Haba et al. 2007), $\sim 4.3 \mathrm{~g} / \mathrm{l}$ of $\mathrm{CDM}$ up to $72 \mathrm{~h}$ using $P$. aeruginosa NCIB 40045 strain (Fernandez et al. 2005), $2.7 \mathrm{~g} / \mathrm{l}$ of CDM using P. stutzeri 1317 strain on soybean oil (He et al. 1998) and by using P. mosselii TO7 CDM ranging from 1.12 to $4.31 \mathrm{~g} / \mathrm{l}$ (Chen et al. 2014).

\section{Production of PHA}

The PHAs from cellular biomass was extracted by solvent extraction and PHA yield was calculated in $\mathrm{g} / \mathrm{l}$ as shown in Fig. 3. The yield of PHA varied for each concentration of carbon source under study. A samimilar increasing trend was observed with all three concentrations. With each

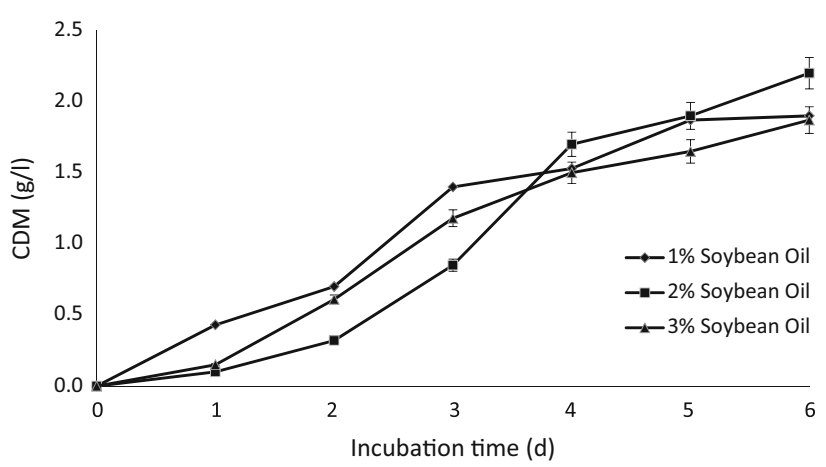

Fig. 2 Cell dry mass (CDM) formation during incubation under shake flask conditions 


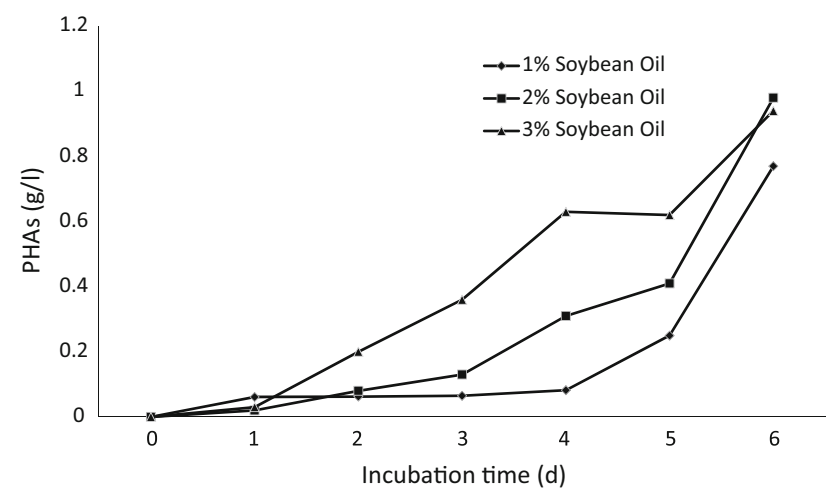

Fig. 3 PHAs production during incubation under shake flask conditions

passing day, the PHAs accumulation increased from 1st to the 6th day of incubation. As the time period passed, the bacteria could had consumed nitrogen thus $\mathrm{C} / \mathrm{N}$ increased which resulted in higher accumulation of PHAs within cells. Maximum PHAs yield of $0.98 \mathrm{~g} / \mathrm{l}$ was obtained on $2 \%(\mathrm{v} / \mathrm{v})$ soybean oil as sole carbon source followed by $3 \%(\mathrm{v} / \mathrm{v})$ soybean oil. PHAs accumulation on biomass also varied, the batch with $3 \%(\mathrm{v} / \mathrm{v})$ soybean oil gave maximum PHAs accumulation of $50.27 \%(\mathrm{w} / \mathrm{w})$ of CDM. This might be due to the fact that PHA accumulation on biomass increased under nitrogen limitations in accordance of already reported work (Basak et al. 2011). The PHAs accumulations of 1,2 and $3 \%(\mathrm{v} / \mathrm{v})$ soybean oil batches were $40.53,44.55$ and $50.27 \%$ (w/w) of CDM, respectively. This could be attributed to the increased value of $\mathrm{C} / \mathrm{N}$ ratio as the concentration of soybean oil was increased. The increased $\mathrm{C} / \mathrm{N}$ is known for enhancing the PHAs accumulation in cells (Durner et al. 2001; Lee et al. 2008; Sudesh et al. 2000). Using oils as carbon source, different reports showed different results with respect to PHAs accumulation in cell biomass; PHAs accumulation up to $36 \%(\mathrm{w} / \mathrm{w})$ of $\mathrm{CDM}$ using $P$. aeruginosa strain (Haba et al. 2007), up to $63 \%$ (w/w) of CDM using Pseudomonas. stutzeri strain (He et al. 1998), from 40 to $50 \%(\mathrm{w} / \mathrm{w})$ PHAs accumulation of CDM using different triglyceride substrates while $44.5 \%(\mathrm{w} / \mathrm{w})$ PHAs accumulation of CDM when grown on soybean oil using Pseudomonas. resinovorans (Ashby and Foglia 1998).

\section{Production kinetics of fermentation}

Kinetic parameters of PHAs production using culture of EBN-8 on different concentrations of soybean oil are shown in Table 1. The bacteria grew and produced PHA on all different concentrations of soybean oil used. After $24 \mathrm{~h}$ of incubation, the biomass began to increase and reached maximum value on the 6th day of incubation in all samples, though the per day increment was different with all three concentrations. The EBN-8 mutant showed the best growth yield coefficient $\left(Y_{\mathrm{X} / \mathrm{S}}\right)$ of $0.369 \mathrm{~g}$ biomass per gram of soybean oil for both 2 and $3 \%(\mathrm{v} / \mathrm{v})$ soybean oil cultures. The value of $Y_{\mathrm{X} / \mathrm{S}}$ increased as the concentration of soybean oil was increased from 1 to 2 and then $3 \%$ (v/ v). The product yield related to substrate $\left(Y_{\mathrm{P} / \mathrm{S}}\right)$ was different for all concentrations and maximum value of $Y_{\mathrm{P} / \mathrm{S}}$ was 0.185 g product per gram of substrate when $3 \%(\mathrm{v} / \mathrm{v})$ soybean oil was used for growth, while 2 and $1 \%(\mathrm{v} / \mathrm{v})$ soybean oil cultures showed only $Y_{\mathrm{P} / \mathrm{S}}$ of 0.164 and $0.098 \mathrm{~g} / \mathrm{g}$, respectively. Maximum product yield with respect to biomass $\left(Y_{\mathrm{P} / \mathrm{X}}\right)$ was $0.503 \mathrm{~g} / \mathrm{g}$ achieved on using $3 \%(\mathrm{v} / \mathrm{v})$ soybean oil followed by $2 \%(\mathrm{v} / \mathrm{v})$ soybean oil as $0.445 \mathrm{~g} / \mathrm{g}$, while only $0.405 \mathrm{~g} / \mathrm{g}$ value was observed using $1 \%(\mathrm{v} / \mathrm{v})$ soybean oil and this could be attributed to the $\mathrm{C} / \mathrm{N}$ ratio increment which plays a significant role in PHA accumulation (Lee et al. 2008; Singh Saharan et al. 2014) and as concentration of soybean oil was increased from 1 to 2 and $3 \%(\mathrm{v} / \mathrm{v})$ soybean oil, the $\mathrm{C} / \mathrm{N}$ ratio also increased favoring more PHA accumulation hence $Y_{\mathrm{P} / \mathrm{X}}$ increased. Maximum volumetric productivity $\left(P_{\mathrm{V}}\right)$ of $0.0068 \mathrm{~g} / \mathrm{l} / \mathrm{h}$ was achieved on $2 \%(\mathrm{v} / \mathrm{v})$ soybean oil cultures followed by $0.0065 \mathrm{~g} / \mathrm{l} / \mathrm{h}$ on $3 \%(\mathrm{v} / \mathrm{v})$ soybean oil cultures which might be due to the less quantity of biomass $(1.9 \mathrm{~g} / \mathrm{l})$ on $3 \%$ soybean oil cultures as compared to the biomass $(2.2 \mathrm{~g} / \mathrm{l})$ achieved on $2 \%$ soybean oil cultures. The $P_{\mathrm{v}}$ of PHAs, using different strains of Pseudomonas species, reported in the literature are $0.012-0.11 \mathrm{~g} / \mathrm{l} / \mathrm{h}$ (Tripathi et al. 2011) and $0.004 \mathrm{~g} / \mathrm{l} / \mathrm{h}$ (Kenny et al. 2008). Muhr et al. (2013a) reported $P_{\mathrm{v}}$ of $0.036-0.067 \mathrm{~g} / \mathrm{l} / \mathrm{h}$ from $P$. citronellolis grown on animal derived waste at bioreactor level. The reason of low $P_{\mathrm{v}}$ of the present study might be the difference of fermentation mode (batch vs fed-batch) but we observed significantly higher values of PHA accumulation of CDM $(50.27 \% \mathrm{w} / \mathrm{w})$ as compared to the CDM (9.2\% w/w), achieved by Muhr et al. (2013a).

\section{Chemical analysis of the product}

For the confirmation of the extracted polymer, it was checked against standard PHB purchased from SigmaAldrich $^{\circledR}$. The FTIR spectra of the standard PHB and extracted PHAs are shown in Figs. 4 and 5, respectively. The standard PHB showed peaks at $1720.33 \mathrm{~cm}^{-1}$ which showed the presence of ester group $(\mathrm{C}=\mathrm{O})$ in the backbone of the structure and absorption range from 1053 to $1280 \mathrm{~cm}^{-1}$ showed the valance vibrations of the carbonyl group as reported in the literature (Biradar et al. 2015). The spectra of extracted PHAs showed peak from 1705.60 to $1738.85 \mathrm{~cm}^{-1}$ which represented ester group in the structure.The peaks in the range of $2848.77-3008.35 \mathrm{~cm}^{-1}$ showed the presence of $\mathrm{CH}_{3}-,-\mathrm{CH}_{2-}-\mathrm{CH}_{2}-,-\mathrm{CH}_{2}-\mathrm{CH}_{3}$ 
Table 1 Kinetic parameters of PHA production by P. aeruginosa EBN-8 on soybean oil

\begin{tabular}{lllll}
\hline Carbon source level & $Y_{\mathrm{X} / \mathrm{S}}(\mathrm{g} / \mathrm{g})$ & $Y_{\mathrm{P} / \mathrm{S}}(\mathrm{g} / \mathrm{g})$ & M PHA/CDM $(\mathrm{g} / \mathrm{g})$ & $P_{\mathrm{V}}(\mathrm{g} / \mathrm{l} / \mathrm{h})$ \\
\hline $1 \%$ soybean oil & $0.243 \pm 0.024$ & $0.098 \pm 0.009$ & $0.405 \pm 0.040$ & $0.0053 \pm 0.005$ \\
$2 \%$ soybean oil & $0.369 \pm 0.037$ & $0.164 \pm 0.016$ & $0.445 \pm 0.044$ & $0.0068 \pm 0.006$ \\
$3 \%$ soybean oil & $0.369 \pm 0.037$ & $0.185 \pm 0.018$ & $0.503 \pm 0.050$ & $0.0065 \pm 0.006$ \\
\hline
\end{tabular}

Fig. 4 FTIR spectra of a PHB and $\mathbf{b}$ PHA produced by $P$. aeruginosa grown on $n$ hexadecane as carbon source
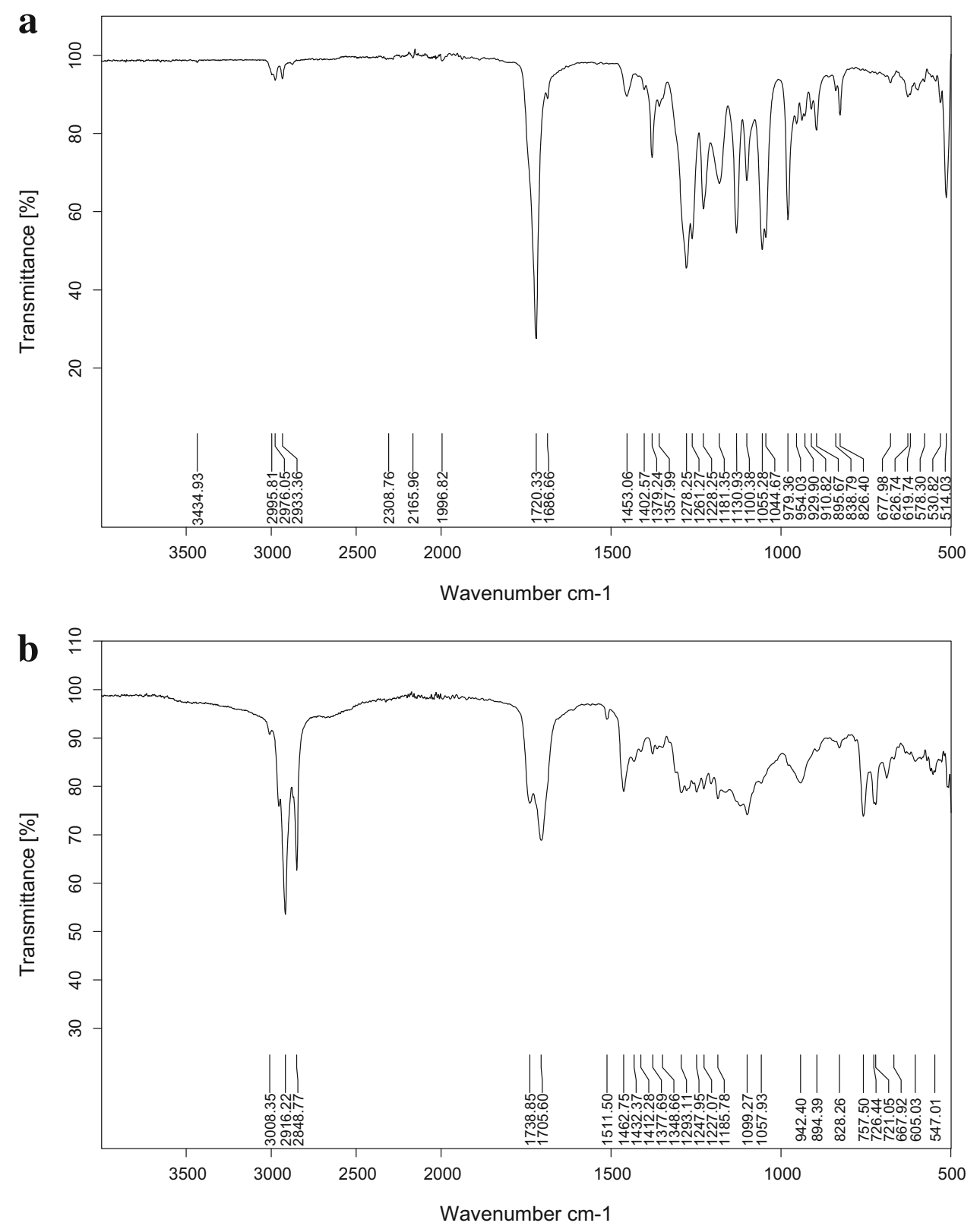

(Gumel et al. 2014). The absorption at $1377.69 \mathrm{~cm}^{-1}$ could be attributed to the terminal $\mathrm{CH}_{3}$ groups present as mentioned in the literature at $1378.83 \mathrm{~cm}^{-1}$ (Vishnuvardhan Reddy et al. 2008).
The FTIR analysis confirmed the peaks near 1738.85, 2916.22, 2848.77 and $1099.27 \mathrm{~cm}^{-1}$ that concluded that produced biopolymer was mcl-PHA copolyesters due to the major difference in peaks near $2900 \mathrm{~cm}^{-1}$ of pure PHB and 

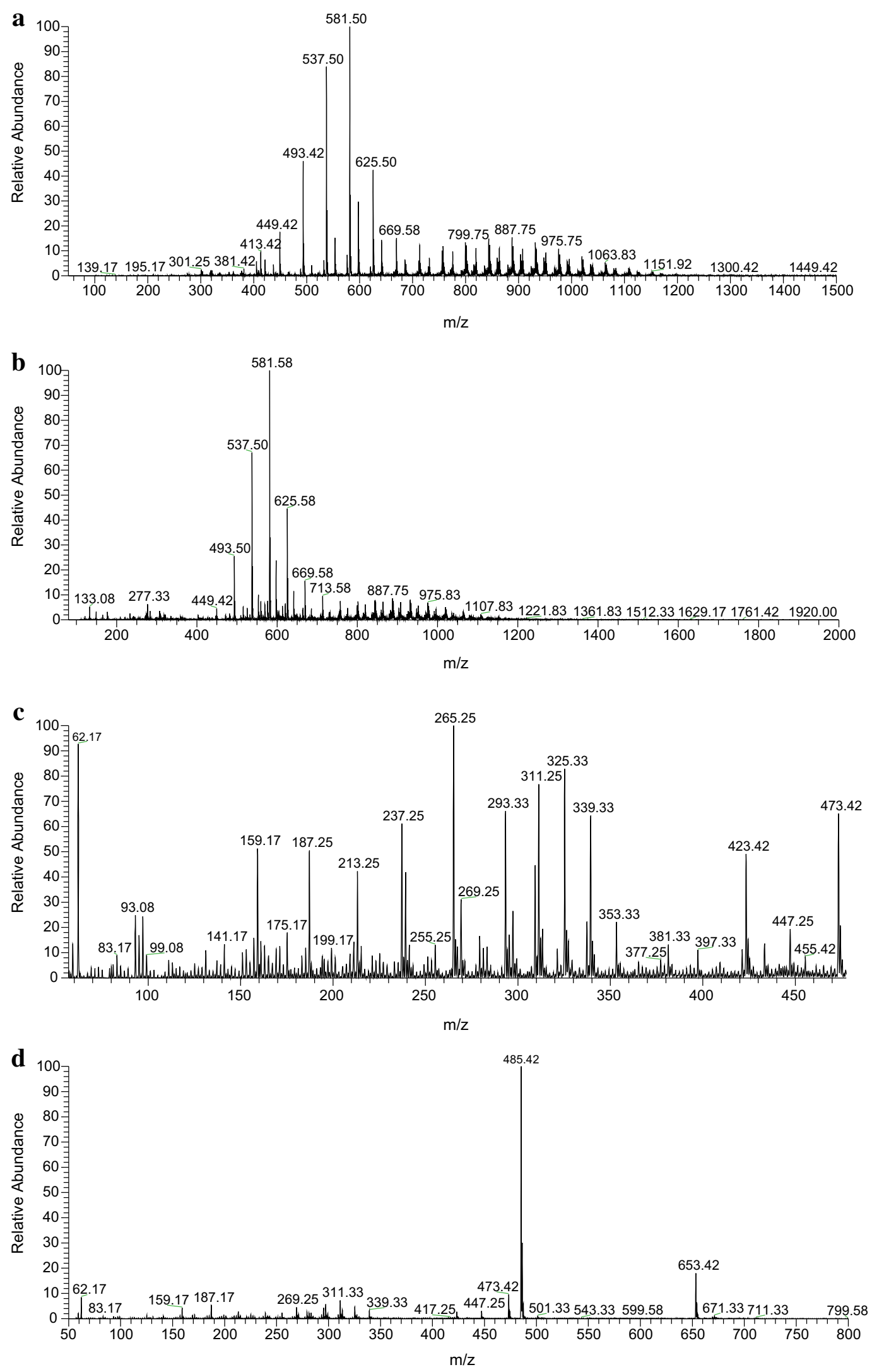

Fig. 5 Representative LC-ESI-MS positive mode spectra of a PHB and $\mathbf{b}$ produced PHA; and respective negative mode spectra of a PHB and b produced PHA 
biosynthesized PHAs (Hong et al. 1999; Khare et al. 2014; Kim et al. 2007).

The LC-ESI-MS analysis of the PHA showed a polymer with the molecular mass of $\mathrm{m} / \mathrm{z} 448.5$ (Fig. 5). Molecular mass of terminal groups was calculated to be 104.5 and that of monomer unit it was 86 . The degree of polymerization of produced PHB was observed as 4 . Hence, the net molecular mass of polymer was calculated by using the following expression:

$$
\begin{aligned}
\text { Mol.mass of PHA } & =104.5+86.0 \times 4 \\
& =104.5+344=\mathbf{4 4 8 . 5} \mathrm{amu} .
\end{aligned}
$$

Hence, the molecular mass of produced PHA was found to be 448.5 , due to positive ionization phenomenon of mass spectra proton of both standard PHB and produced PHAs molecules yielded $[\mathrm{M}+\mathrm{H}]^{+}$cations at $m / z, 449.5$ which can be seen from the spectra giving the confirmation of the compound (Fig. 5a, b). Whereas, the negative mode ESIMS of both standard PHB and produced PHAs molecules yielded $[\mathrm{M}-\mathrm{H}]^{-}$anions at $\mathrm{m} / \mathrm{z} 447.5$ which can be seen from the spectra giving the confirmation of the compound (Fig. 5c, d). Hence, confirming that the polymer has four basic repeated units linked in a chain forming the PHB structure. Pseudomonas aeruginosa has been reported already for the production of PHB (Ayub et al. 2004; Lopez et al. 2009). The mass spectra also showed some other peaks which indicated that other monomers apart from PHB are also present, which require further characterization in future by GC-FID and GC-MS.

\section{Conclusion}

In the present report, polyhydroxyalkanoates production and optimization was done using a Pseudomonas aeurginosa strain grown on different concentrations of soybean oil. Maximum yield of polyhydroxyalkanoates as $0.98 \mathrm{~g} / \mathrm{l}$ and the maximum volumetric productivity as $0.0068 \mathrm{~g} / \mathrm{l} / \mathrm{h}$ were achieved on $2 \%(\mathrm{v} / \mathrm{v})$ soybean oil cultures, while the maximum polyhydroxyalkanoates accumulation percentage $50.27 \%(\mathrm{w} / \mathrm{w})$ of cell dry mass achieved was on $3 \%$ $(\mathrm{v} / \mathrm{v})$ soybean oil culture. The cultures with $3 \%(\mathrm{v} / \mathrm{v})$ soybean oil also showed the maximum product yield per gram of substrate and biomass which were 0.185 and $0.503 \mathrm{~g} / \mathrm{g}$, respectively.

\section{Future work}

The selected gamma ray mutant of Pseudomonas aeurginosa showed good biosynthesis of polyhydroxyalkanoates under shake flask conditions when grown on soybean oil. The strain can be switched up on fermentor (large scale) for the production of polyhydroxyalkanoates, which can be optimized further to achieve economical polyhydroxyalkanoates production. Furthermore, the characterization of the produced biopolymers with GC-FID and GC-MS for monomeric composition analysis.

Acknowledgments The authors acknowledge Higher Education Commission, Islamabad, Pakistan for research grant (NRPU-3154).

\section{Compliance with ethical standards}

Conflict of interest The authors declare that they have no conflict of interest.

Open Access This article is distributed under the terms of the Creative Commons Attribution 4.0 International License (http:// creativecommons.org/licenses/by/4.0/), which permits unrestricted use, distribution, and reproduction in any medium, provided you give appropriate credit to the original author(s) and the source, provide a link to the Creative Commons license, and indicate if changes were made.

\section{References}

Aiba S, Humphrey AE, Millis NF (1973) Biochemical engineering, 2nd edn. Academic Press, New york

Ashby RD, Foglia TA (1998) Poly(hydroxyalkanoate) biosynthesis from triglyceride substrates. Appl Microbiol Biotechnol 49:431-437. doi:10.1007/s002530051194

Ayub ND, Pettinari MJ, Ruiz JA, Lopez NI (2004) A polyhydroxybutyrate-producing Pseudomonas sp. isolated from antarctic environments with high stress resistance. Curr Microbiol 49:170-174. doi:10.1007/s00284-004-4254-2

Basak B, Ince O, Artan N et al (2011) Effect of nitrogen limitation on enrichment of activated sludge for PHA production. Bioprocess Biosyst Eng 34:1007-1016. doi:10.1007/s00449-011-0551-x

Biradar GG, Shivasharana CT, Kaliwal BB (2015) Isolation and characterization of polyhydroxybutyrate (PHB) producing Bacillus species from agricultural soil. Eur J Exp Biol 5:58-65

Brown BS (1996) Biological membranes. Biochem Soc 8:2-4

Chalmers JM, Everall NJ, Ellison S (1996) Specular reflectance: a convenient tool for polymer characterization by FTIR-microscopy. Micron 27:315-328. doi:10.1016/S0968-4328(96)00021-2

Chee JY, Yoga SS, Lau NS et al (2010) Bacterially produced polyhydroxyalkanoate (PHA): converting renewable resources into bioplastics. In: Méndez-Vilas A (ed) Current research, technology and education topics in applied microbiology and microbial biotechnology. Formatex Research Center, Spain, pp 1395-1404

Chen GQ (2010) Plastics completely synthesized by bacteria: polyhydroxyalkanoates. Plastics from bacteria. Springer, Berlin, pp 17-37

Chen YJ, Huang YC, Lee CY (2014) Production and characterization of medium chain length polyhydroxyalkanoates by Pseudomonas mosselii TO7. J Biosci Bioeng 118:145-152. doi:10. 1016/j.jbiosc.2014.01.012

Durner R, Zinn M, Witholt B, Egli T (2001) Accumulation of poly[(R)-3-hydroxyalkanoates] in Pseudomonas oleovorans during growth in batch and chemostat culture with different carbon sources. Biotechnol Bioeng 72:278-288

Fernandez D, Rodriguez E, Bassas M et al (2005) Agro-industrial oily wastes as substrates for PHA production by the new strain Pseudomonas aeruginosa NCIB 40045: effect of culture conditions. Biochem Eng J 26:159-167. doi:10.1016/j.bej.2005.04. 022 
Gumel AM, Annuar MSM, Heidelberg T (2014) Growth kinetics, effect of carbon substrate in biosynthesis of mcl-PHA by Pseudomonas putida Bet001. Braz J Microbiol 45:427-438

Haba E, Espuny MJ, Busquets M, Manresa A (2000) Screening and production of rhamnolipids by Pseudomonas aeruginosa 47T2 NCIB 40044 from waste frying oils. J Appl Microbiol 88:379-387

Haba E, Vidal Mas J, Bassas M et al (2007) Poly 3-(hydroxyalkanoates) produced from oily substrates by Pseudomonas aeruginosa 47T2 (NCBIM 40044): effect of nutrients and incubation temperature on polymer composition. Biochem Eng J 35:99-106. doi:10.1016/j.bej.2006.11.021

He W, Tian W, Zhang G et al (1998) Production of novel polyhydroxyalkanoates by Pseudomonas stutzeri 1317 from glucose and soybean oil. FEMS Microbiol Lett 169:45-49. doi:10.1016/S0378-1097(98)00462-5

Hong K, Sun S, Tian W et al (1999) A rapid method for detecting bacterial polyhydroxyalkanoates in intact cells by fourier transform infrared spectroscopy. Appl Microbiol Biotechnol 51:523-526. doi:10.1007/s002530051427

Hori K, Marsudi S, Unno H (2002) Simultaneous production of polyhydroxyalkanoates and rhamnolipids by Pseudomonas aeruginosa. Biotechnol Bioeng 78:699-707. doi:10.1002/bit. 10248

Iqbal S, Khalid ZM, Malik KA (1995) Enhanced biodegradation and emulsification of crude oil and hyperproduction of biosurfactants by a gamma ray-induced mutant of Pseudomonas aeruginosa. Lett Appl Microbiol 21:176-179

Jacquel N, Lo CW, Wei YH et al (2008) Isolation and purification of bacterial poly(3-hydroxyalkanoates). Biochem Eng J 39:15-27

Jiang Y, Song X, Gong L et al (2008) High poly(hydroxybutyrate) production by Pseudomonas fluorescens A2a5 from inexpensive substrates. Enzyme Microb Technol 42:167-172. doi:10.1016/j. enzmictec.2007.09.003

Kenny ST, Runic JN, Kaminsky W et al (2008) Up-cycling of PET (polyethylene terephthalate) to the biodegradable plastic PHA (polyhydroxyalkanoate). Environ Sci Technol 42:7696-7701

Khandpur P, Jabeen ET, Rohini KVL, Varaprasad Y (2012) Study on production, extraction and analysis of polyhydroxyalkanoate (PHA) from bacterial isolates. IOSR J Pharm Biol Sci IOSRJBPS 1:31-38

Khare E, Chopra J, Arora NK (2014) Screening for mcl-PHAproducing fluorescent Pseudomonads and comparison of mclPHA production under iso-osmotic conditions induced by PEG and NaCl. Curr Microbiol 68:457-462. doi:10.1007/s00284-0130497-0

Kim DY, Kim HW, Chung MG, Rhee YH (2007) Biosynthesis, modification, and biodegradation of bacterial medium chain length polyhydroxyalkanoates. J Microbiol 45:87-97

Koley D, Bard AJ (2010) Triton X-100 concentration effects on membrane permeability of a single $\mathrm{HeLa}$ cell by scanning electrochemical microscopy (SECM). Proc Natl Acad Sci USA 107:16783-16787. doi:10.1073/pnas.1011614107

Koller M, Rodríguez-Contreras A (2015) Techniques for tracing PHA-producing organisms and for qualitative and quantitative analysis of intra- and extracellular PHA. Eng Life Sci 15:558-581. doi:10.1002/elsc.201400228

Koller M, Salerno A, Muhr A et al (2012) Polyhydroxyalkanoates: biodgradable polymers and plastics from renewable resources. Mater Technol 46:23-30

Kumar S, Abe H (2010) Practical guide to microbial polyhydroxyalkanoates. Smithers Rapra, Shropshire

Lee WH, Loo CY, Nomura CT, Sudesh K (2008) Biosynthesis of polyhydroxyalkanoate copolymers from mixtures of plant oils and 3-hydroxyvalerate precursors. Bioresour Technol 99:6844-6851. doi:10.1016/j.biortech.2008.01.051
Loo C, Sudesh K (2007) Polyhydroxyalkanoates: bio-based microbial plastics and their properties. Malays Polym J 2:31-57

Lopez NI, Pettinari MJ, Stackebrandt E et al (2009) Pseudomonas extremaustralis sp. nov., a poly(3-hydroxybutyrate) producer isolated from an antarctic environment. Curr Microbiol 59:514-519. doi:10.1007/s00284-009-9469-9

Marsudi S, Unno H, Hori K (2008) Palm oil utilization for the simultaneous production of polyhydroxyalkanoates and rhamnolipids by Pseudomonas aeruginosa. Appl Microbiol Biotechnol 78:955-961. doi:10.1007/s00253-008-1388-3

Muhr A, Rechberger EM, Salerno A et al (2013a) Biodegradable latexes from animal-derived waste: biosynthesis and characterization of mcl-PHA accumulated by Ps. citronellolis. React Funct Polym 73:1391-1398. doi:10.1016/j.reactfunctpolym. 2012.12.009

Muhr A, Rechberger EM, Salerno A et al (2013b) Novel description of mcl-PHA biosynthesis by Pseudomonas chlororaphis from animal-derived waste. J Biotechnol 165:45-51. doi:10.1016/j. jbiotec.2013.02.003

Pollet E, Averous L (2011) Production, chemistry and properties of polyhydroxyalkanoates. In: Plackett D (ed) Biopolymers-new materials for sustainable films and coatings, 1st edn. Wiley, Chichester, pp 65-86

Prasad MP, Sethi R (2013) Production and isolation of polyhydroxyalkanoates from Pseudomonas sp. using waste cooking oil as a sole carbon source. Int J Adv Biotechnol Res 4:527-532

Raza ZA, Khan MS, Khalid ZM, Rehman A (2006) Production kinetics and tensioactive characteristics of biosurfactant from a Pseudomonas aeruginosa mutant grown on waste frying oils. Biotechnol Lett 28:1623-1631. doi:10.1007/s10529-0069134-3

Raza ZA, Rehman A, Hussain MT et al (2014) Production of rhamnolipid surfactant and its application in bioscouring of cotton fabric. Carbohydr Res 391:97-105. doi:10.1016/j.carres. 2014.03.009

Silva-Queiroz SR, Silva LF, Pradella JGC et al (2009) PHA(MCL) biosynthesis systems in Pseudomonas aeruginosa and Pseudomonas putida strains show differences on monomer specificities. J Biotechnol 143:111-118. doi:10.1016/j.jbiotec.2009.06. 014

Singh Saharan B, Grewal A, Kumar P (2014) Biotechnological production of polyhydroxyalkanoates: a review on trends and latest developments. Chin J Biol 2014:1-18. doi:10.1155/2014/ 802984

Soberon-Chavez G, Aguirre-Ramirez M, Sanchez R (2005a) The Pseudomonas aeruginosa RhlA enzyme is involved in rhamnolipid and polyhydroxyalkanoate production. J Ind Microbiol Biotechnol 32:675-677. doi:10.1007/s10295-005-0243-0

Soberon-Chavez G, Lepine F, Deziel E (2005b) Production of rhamnolipids by Pseudomonas aeruginosa. Appl Microbiol Biotechnol 68:718-725. doi:10.1007/s00253-005-0150-3

Song JH, Jeon CO, Choi MH et al (2008) Polyhydroxyalkanoate (PHA) production using waste vegetable oil by Pseudomonas sp. strain DR2. J Microbiol Biotechnol 18:1408-1415

Sudesh K (2012) Polyhydroxyalkanoates from palm oil: biodegradable plastics, 1st edn. Springer, Berlin

Sudesh K, Abe H, Doi Y (2000) Synthesis, structure and properties of polyhydroxyalkanoates: biological polyesters. Prog Polym Sci 25:1503-1555. doi:10.1016/S0079-6700(00)00035-6

Tan GY, Chen CL, Li L et al (2014) Start a research on biopolymer polyhydroxyalkanoate (PHA): a review. Polymers 6:706-754. doi:10.3390/polym6030706

Tripathi AD, Yadav A, Jha A, Srivastava SK (2011) Utilizing of sugar refinery waste (cane molasses) for production of bio-plastic under submerged fermentation process. J Polym Environ 20:446-453. doi:10.1007/s10924-011-0394-1 
Verlinden R, Hill DJ, Kenward MA et al (2007) Bacterial synthesis of biodegradable polyhydroxyalkanoates. J Appl Microbiol 102:1437-1449. doi:10.1111/j.1365-2672.2007.03335.x

Vishnuvardhan Reddy S, Thirumala M, Mahmood SK (2008) Production of $\mathrm{PHB}$ and $\mathrm{P}$ (3HB-co-3HV) biopolymers by Bacillus megaterium strain OU303A isolated from municipal sewage sludge. World J Microbiol Biotechnol 25:391-397. doi:10.1007/s11274-008-9903-3

Williams SF, Martin DP, Horowitz DM, Peoples OP (1999) PHA applications: addressing the price performance issue I. Tissue engineering. Int J Biol Macromol 25:111-121 